\title{
Molecular Jamming in Tortuous Nanochannels
}

Petr Dementyev, ${ }^{*, \dagger}$ Yang Yang, ${ }^{*,+, \ddagger}$ Maria Rezvova, ${ }^{\dagger, \S}$ Armin Gölzhäuser ${ }^{\dagger}$

${ }^{\dagger}$ Physics of Supramolecular Systems and Surfaces, Faculty of Physics, Bielefeld University, Bielefeld, 33615 Germany

${ }^{\ddagger}$ Barrer Centre, Imperial College London, London, SW7 2AZ United Kingdom

${ }^{\S}$ Research Institute for Complex Issues of Cardiovascular Diseases, Kemerovo, 650002 Russian Federation

\section{Corresponding Authors}

*(dementyev@physik.uni-bielefeld.de (P.D.); yang.yang1@imperial.ac.uk (Y.Y.)) 


\section{Synthetic azeotrope}

Water and 1-propanol are fully miscible and form a pressure maximum azeotrope. The vaporliquid equilibria in the binary system have been extensively studied under various conditions. ${ }^{1-}$

${ }^{3}$ It is known that the azeotrope composition varies slightly with temperature, ranging from 60 mol\% $\mathrm{H}_{2} \mathrm{O}$ at $30^{\circ} \mathrm{C}$ to $57 \mathrm{~mol} \% \mathrm{H}_{2} \mathrm{O}$ at $90^{\circ} \mathrm{C}$. Due to the sensitivity reasons, we carry out massspectrometric measurements with $\mathrm{D}_{2} \mathrm{O}$ rather than with $\mathrm{H}_{2} \mathrm{O}$. As there are no data available on thermodynamic behavior of heavy water in mixtures, we performed a simple experiment to check any difference between the isotopologues. Fig. SI1 shows the part of our permeation facility that was used to study $\mathrm{D}_{2} \mathrm{O}-\mathrm{PrOH}$ mixtures. The mixing chamber of $110 \mathrm{~cm}^{3}$ and the coldfinger of $1.4 \mathrm{~cm}^{3}$ were used to prepare binary mixtures of arbitrary composition. Specifically, small portions of each vapor (10 mbar) were first dosed into the mixing chamber and then collected in the coldfinger by freezing with liquid nitrogen. As a result, mostly liquefied mixtures were obtained inside the coldfinger, and following the equilibration to room temperature, the corresponding vapor mixtures were let to the mixing chamber. The substances were taken in an excess amount in order to assure a vapor-liquid equilibrium in the overall volume. Thus, the saturation vapor pressure was measured with the capacitance manometer as a function of the preset total composition $\mathrm{N}_{\text {water }}$ and $\mathrm{N}_{\text {propanol. }}$.

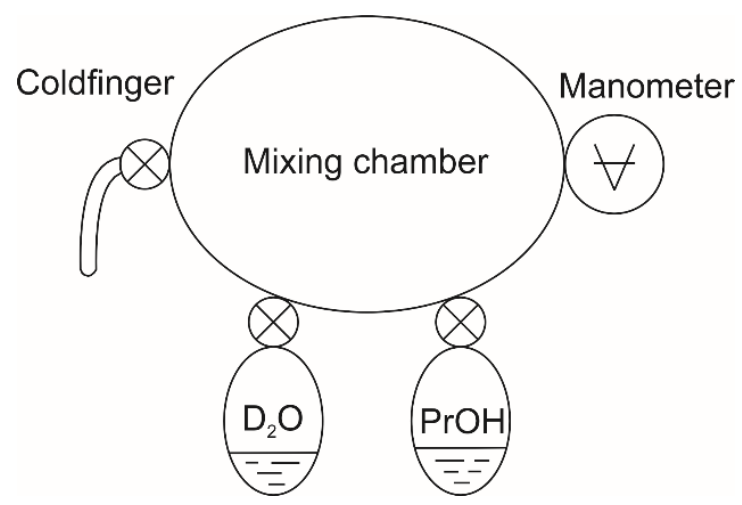

Figure SI1. Schematic of the experiment for measuring vapor pressure in binary heavy waterpropanol mixtures.

Generally, vapor phase composition in non-ideal mixtures differs from that in the liquid phase. Therefore, the molar fractions of heavy water $\mathrm{x}_{\text {water }}$ and $\mathrm{y}_{\text {water }}$ in the liquid and vapor phase can be represented as follows:

$$
x_{\text {water }}=\frac{N_{\text {water }}^{l i q}}{N_{\text {water }}^{l i q}+N_{\text {propanol }}^{l i q}}
$$

and 


$$
y_{\text {water }}=\frac{N_{\text {water }}^{\text {vap }}}{N_{\text {water }}^{\text {vap }}+N_{\text {propanol }}^{\text {vap }}}
$$

respectively.

Here, $N_{\text {water }}=N_{\text {water }}^{l i q}+N_{\text {water }}^{\text {vap }}$ and $N_{\text {propanol }}=N_{\text {propanol }}^{l i q}+N_{\text {propanol }}^{\text {vap }}$ correspond to the initial amounts of the components in accordance with the principle of mass conservation.

By definition, $x_{\text {water }}=y_{\text {water }}$ at the constant boiling point, i.e. at the point of maximum vapor pressure for a positive azeotrope. Now, equating the above expressions, one obtains:

$$
N_{\text {water }}^{\text {liq }} N_{\text {propanol }}^{\text {vap }}=N_{\text {water }}^{\text {vap }} N_{\text {propanol }}^{l i q}
$$

Substituting with $N_{\text {water }}^{l i q}=N_{\text {water }}-N_{\text {water }}^{\text {vap }}$ and $N_{\text {propanol }}^{\text {liq }}=N_{\text {propanol }}-N_{\text {propanol }}^{\text {vap }}$

$$
\frac{N_{\text {water }}}{N_{\text {propanol }}}=\frac{N_{\text {water }}^{\text {vap }}}{N_{\text {propanol }}^{\text {vap }}}
$$

In other words, at the azeotropic point, the composition of the vapor phase matches exactly the as prepared composition of our mixtures. Fig. SI2 (identical to Fig. 3a in the main text) illustrates the results of the pressure measurements (reproduced in Table SI1). There is a clear maximum observed at around $60 \mathrm{~mol} \% \mathrm{D}_{2} \mathrm{O}$ which is very much similar to regular water. These data serve as a solid justification for deploying the heavy water-propanol mixture as a model room temperature azeotrope. For every permeation measurement, the mixture was freshly prepared in situ as described above and supplied directly to a CNM sample.

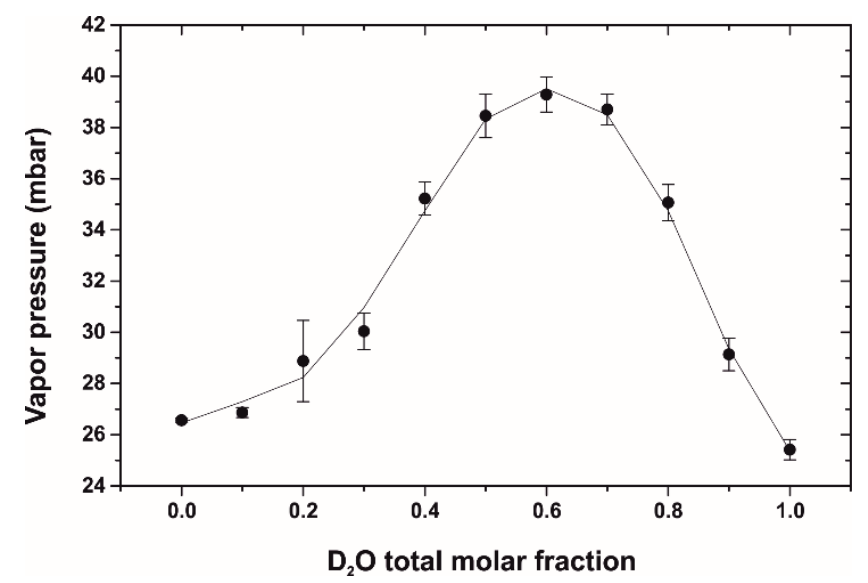

Figure SI2. Saturation vapor pressure in heavy water-propanol mixtures at room temperature. The data points are mean values over 3 measurements, and the error bars are standard deviation. The solid line is for guiding the eye. 
Table SI1. Numerical data depicted in Fig. SI2

\begin{tabular}{|l|l|}
\hline $\begin{array}{l}\text { Molar fraction of heavy water in as- } \\
\text { prepared mixtures }\end{array}$ & $\begin{array}{l}\text { Vapor pressure of released mixtures, } \\
\text { mbar }\end{array}$ \\
\hline 0 & $26.6 \pm 0.1$ \\
\hline 0.1 & $26.9 \pm 0.2$ \\
\hline 0.2 & $28.9 \pm 1.6$ \\
\hline 0.3 & $30.0 \pm 0.7$ \\
\hline 0.4 & $35.2 \pm 0.6$ \\
\hline 0.5 & $38.5 \pm 0.9$ \\
\hline 0.6 & $39.3 \pm 0.7$ \\
\hline 0.7 & $38.7 \pm 0.6$ \\
\hline 0.8 & $35.1 \pm 0.7$ \\
\hline 0.9 & $25.4 \pm 0.6$ \\
\hline 1 & \\
\hline
\end{tabular}

\section{References}

1) R. A. Dawe, D. M. T. Newsham, S. Bee Ng, J. Chem. Eng. Data, 1973, 18, 44.

2) E. B. Munday, J. C. Mullins, D. D. Edle, J. Chem. Eng. Data, 1980, 25, 191.

3) C. Gabaldon, P. Marzal, J. B. Monton, M. A. Rodrigo, J. Chem. Eng. Data, 1996, 41, 1176. 